\title{
Permanent Rare-Earth Magnets-The Need to Protect Them against Corrosion
}

\author{
Célia Aparecida Lino dos Santos', Zehbour Panossian ${ }^{1,2}$ \\ ${ }^{1}$ Corrosion and Protection Laboratory, LCP, Institute for Technological Research-IPT, São Paulo, Brazil \\ ${ }^{2}$ Innovation and Business Officer, DIN, Institute for Technological Research-IPT, São Paulo, Brazil \\ Email: clsantos@ipt.br
}

How to cite this paper: dos Santos, C.A.L. and Panossian, Z. (2019) Permanent Rare-Earth Magnets-The Need to Protect Them against Corrosion. Materials Sciences and Applications, 10, 317-327. https://doi.org/10.4236/msa.2019.104024

Received: January 22, 2019

Accepted: April 8, 2019

Published: April 11, 2019

Copyright () 2019 by author(s) and Scientific Research Publishing Inc. This work is licensed under the Creative Commons Attribution International License (CC BY 4.0).

http://creativecommons.org/licenses/by/4.0/

(c) (i) Open Access

\begin{abstract}
The RE-Fe-B permanent magnets have a complex microstructure and they are susceptible to corrosion process. In this paper, the commercial nickel coatings adhesion was investigated. The microstructure of the RE-Fe-B without coating was analyzed by scanning electronic microscopy and electrochemical techniques. The interface magnet/coating was studied by scanning electron microscopy and the nickel-plated Nd-Fe-B commercial magnets were tested in a salt spray chamber. The ferromagnetic and RE-rich phases were observed. After the anodic polarization curve, a strong intergranular corrosion was observed and the RE-rich phase was preferentially attacked. The interface magnet/Ni coating presented intergranular corrosion that can affect the nickel coating adherence. This attack had probably occurred during the electrodeposition process. Not all the samples suffered localized corrosion during the salt spray tests and the Ni triple-layer coating presented a few corrosion points. RE-Fe-B alloy magnets need to be protected with appropriate coatings to each environment to which they will be exposed and the protective coating must not be damaged.
\end{abstract}

\section{Keywords}

Permanent Magnet, Rare-Earth, Corrosion, Protection against Corrosion

\section{Introduction}

One of the main industrial applications of rare-earth metals (RE) is the permanent magnets production. Nowadays, permanent magnets are used in wind power, electronics, electric vehicles and other fields. China is the world's largest supplier of RE products and the international market leader. China has always strictly controlled exports of RE and, in 2012, had imposed a restriction of RE 
supply quotas which spooked the international market and brought insecurity regarding the supply of these metals [1].

Some initiatives around the world are being conducted for the RE production to minimize China's dependency [2]. In Brazil, studies are underway to produce $\mathrm{RE}$ oxides and metals, as well as, to propose projects to establish a productive chain in the country, namely the development of companies that deal with the mineral extraction, collection and separation of oxides, reduction of metals, production of alloys, production of permanent magnets and, finally, magnet consumption companies [3].

Permanent magnets production is a complex process [4] because RE-Fe- $\mathrm{B}$ magnets are based on three phases: the ferromagnetic phase ( $\phi$, iron rich) which, when magnetized, produces the external magnetic field and the non-magnetic phase, rich in RE elements. The latter promotes the phase $(\phi)$ grain isolation by a thin layer formation. The amount of non-ferromagnetic phase should be enough only to isolate the phase ( $\phi$ ) grains to avoid negative impacts on magnet remanence due to the dilution of the ferromagnetic phase [5]. Besides these phases, there is also a rich boron phase ( $\eta)[6]$.

These phases in magnet microstructure have different corrosion potentials that lead a poor corrosion resistance [6]. It is possible to improve the corrosion resistance by adding alloying elements such as $\mathrm{Co}, \mathrm{Nb}, \mathrm{V}, \mathrm{Mo}, \mathrm{Cu}$ and $\mathrm{Ga}$ in the magnet [7] or applying coatings. The most common protective coatings are the metallic, conversion (phosphatized as a temporary protection) and organic (paint) layers [8].

Commercially, electrodeposited metallic coatings are well accepted by the consumer market. However, lack of adhesion of the protective layer can be observed.

The aim of this work is to verify the commercial nickel coatings adhesion by the characterization of nickel-plated Nd-Fe-B commercial magnets. Coated magnets and $\mathrm{Nd}-\mathrm{Fe}-\mathrm{B}$ itself were studied by scanning electron microscopy, salt spray tests and electrochemical tests (potential monitoring and potentiodynamic polarization).

\section{Materials and Methods}

\subsection{Samples}

Rectangular blocks ( $40 \mathrm{~mm} \times 20 \mathrm{~mm} \times 5 \mathrm{~mm}$ ) of Nd-Fe-B commercial magnets (N28) were studied, all of them with a nickel electrodeposit, Figure 1.

The magnet blocks were studied under magnetized (salt spray tests) and under demagnetized conditions (microstructure characterization, salt sprays tests and electrochemical tests). Two demagnetizing processes were used, heat treatment at $335^{\circ} \mathrm{C}(\mathrm{HT})$ for one hour and under an opposite magnetic field (OMF).

The magnets microstructure characterization was made by a scanning electron microscopy-SEM (FEG-Field Emission Gun, FEI manufacturer, Quanta model 400F and X-EDS energy dispersion spectroscopy) before and after the salt spray and the electrochemical tests. 


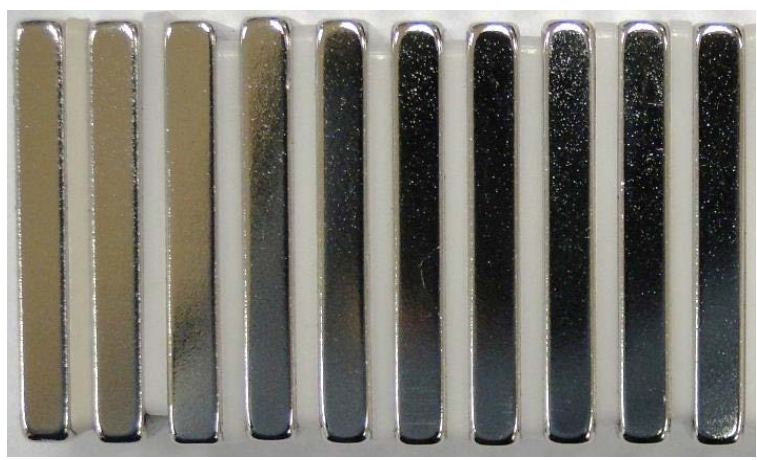

(a)

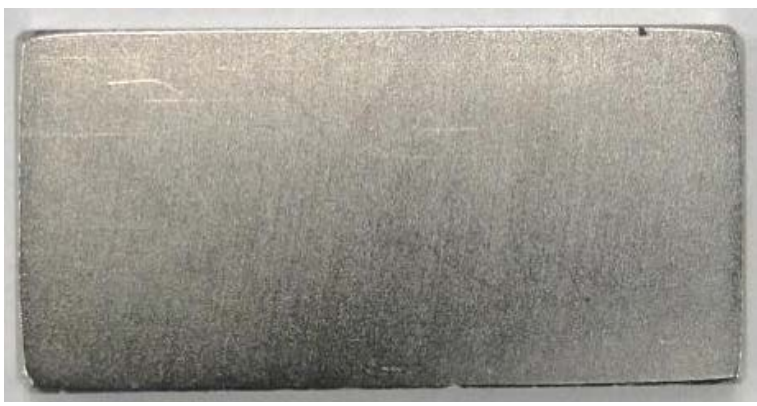

(b)

Figure 1. Images of commercial nickel-plated Nd-Fe-B magnets. (a) Side view; (b) Front view.

\subsection{Electrochemical Tests}

The magnets were studied by electrochemical tests. For this, demagnetized blocks were cut to obtain a cube with $1.0 \mathrm{~cm}$ of an uncoated side. This cube was embedded in Bakelite and the uncoated surface of $1.0 \mathrm{~cm}^{2}$ was polished using diamond paste $(1 \mu \mathrm{m})$ prior to the electrochemical tests. A conventional electrochemical system with three electrodes was used: the uncoated magnetic alloy as the working electrode, a saturated calomel electrode as a reference electrode and a rectangular platinum gauze as an auxiliary electrode. A solution containing $0.05 \mathrm{~mol} / \mathrm{L} \mathrm{NaCl}, \mathrm{pH}=6.7$, was used as an electrolyte.

Open potential circuit measurements (OPC curves) for 10,600 s ( $3 \mathrm{~h}$ ) and potentiodynamic polarization curves (PPC) were made. For PPC, a potentiostat/galvanostat PAR model 2273 was used, adopting a scanning rate of 0.166 $\mathrm{mV} / \mathrm{s}$. The anodic potentiodynamic polarization curves (APPC) started at the OCP up to $-0.300 \mathrm{~V} / \mathrm{ECS}$ and the cathodic potentiodynamic polarization curves (CPPC) swept from the OCP down to $-1300 \mathrm{~V} / \mathrm{ECS}$. The tests were conducted at room temperature $(23 \pm 2)^{\circ} \mathrm{C}$.

\subsection{Salt Spray Tests}

Salt spray tests were done positioning three magnetized and three demagnetized samples (only triple-layer $\mathrm{Ni}$ coating) in a chamber in which a $5 \% \mathrm{NaCl}$ solution was continuously sprayed at $(35 \pm 2)^{\circ} \mathrm{C}$ for $72 \mathrm{~h}$. The $\mathrm{pH}$ of the solution was between 6.5 and 7.2 and the relative humidity was $100 \%$. 


\section{Results and Discussions}

\subsection{Microstructure Characterization}

Figure 2 presents magnet SEM images of demagnetized samples by HT and by OMF, the gray areas are related to ferromagnetic phases $(\phi)$ while the white areas are related to $\mathrm{RE}$-rich phases.

In Table 1, we present the EDS obtained results in red highlighted areas in Figure 2(a) and Figure 2(b).

For both characterized samples, the RE content $(\mathrm{Nd}+\mathrm{Pr})$ was $29 \%$ and the iron content was $66 \%$ (Table 1). These values are close to the values of the alloys (Nd-Pr)-Fe-B observed in the literature [7].

The HT demagnetizing should generate some cracks and holes in the alloy

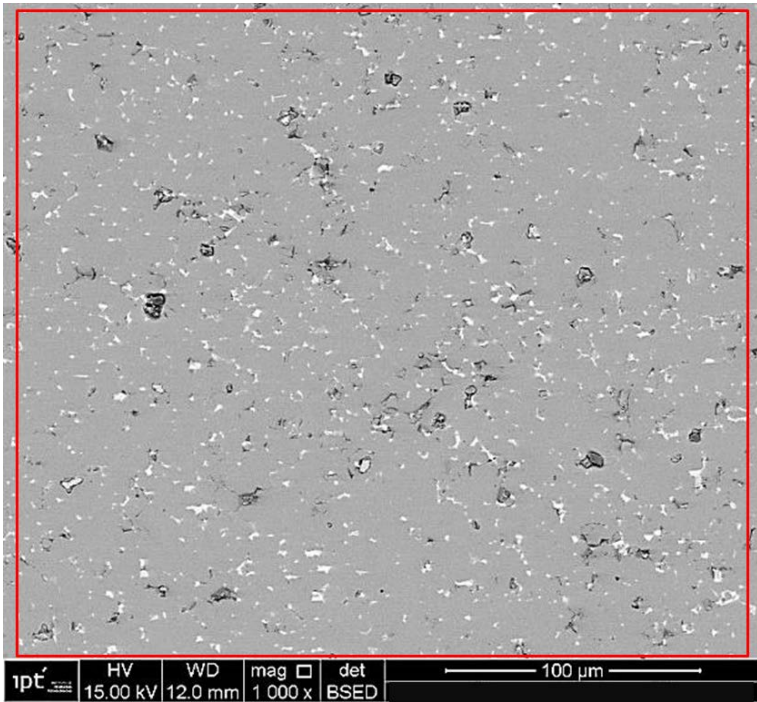

(a)

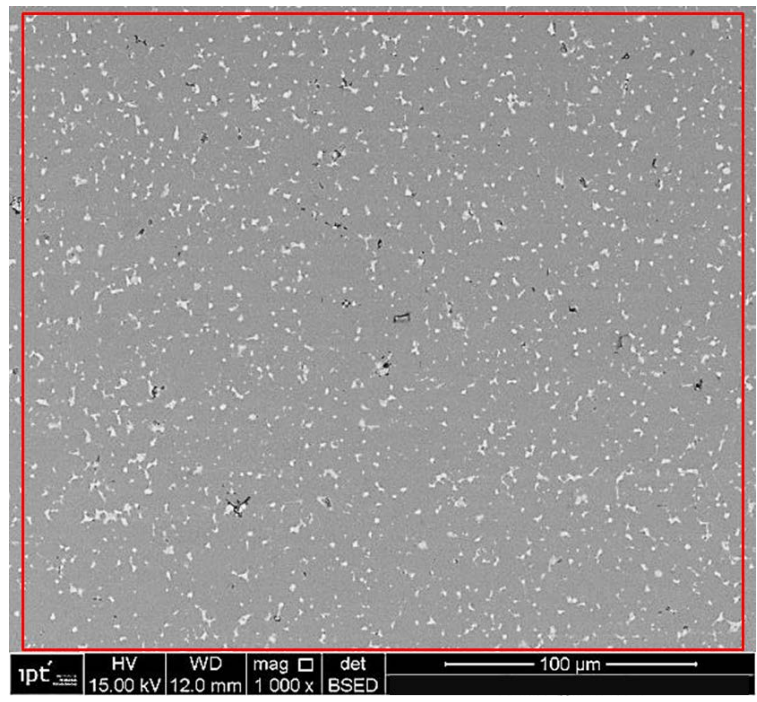

(b)

Figure 2. SEM images of Nd-Fe-B magnets samples. (a) HT demagnetized; (b) OMF demagnetized. 
Table 1. EDS results of analyzed areas shown in Figure 2(a) and Figure 2(b).

\begin{tabular}{ccccc}
\hline \multirow{2}{*}{ Element } & \multicolumn{2}{c}{ HT } & \multicolumn{2}{c}{ OMF } \\
\cline { 2 - 5 } & \% mass & \% atomic & \% mass & \% atomic \\
\hline B & 2.37 & 12.52 & 2.27 & 12.21 \\
O & 2.18 & 7.80 & 1.88 & 6.82 \\
Fe & 66.61 & 68.18 & 66.27 & 68.98 \\
Pr & 6.52 & 2.64 & 6.69 & 2.76 \\
Nd & 22.32 & 8.85 & 22.88 & 9.22 \\
Total & 100.00 & 99.99 & 99.99 & 99.99 \\
\hline
\end{tabular}

microstructure (Figure 2(a)). In view of this, the demagnetizing by HT was abandoned. Therefore, salt spray and electrochemical tests were done with OMF treated samples.

Nickel coatings were analyzed by SEM-FEG and two types of coatings were observed: single layer (HT demagnetized) and triple layer (OMF demagnetized). SEM-FEG images are presented in Figure 3 in which the thicknesses of the layers were highlighted.

Figure 3(a) and Figure 3(b) images show intergranular corrosion inside the substrate near the alloy/coating interface for both kinds of nickel coatings. This corrosion probably occurred during the electrodeposition step and can affect the nickel coating adherence. Therefore, electrodeposition baths should be selected in such a way as to use formulations that do not damage the surface of the magnets to avoid the occurrence of intergranular corrosion, since $\mathrm{Nd}$ phase-rich is attacked.

The EDS analyses showed that the single layer coating was composed of only nickel (Figure 3(a)) and the triple layer coating composed of nickel (C), copper (B) and nickel (A) (Figure 3(b)). Table 2 shows the thickness values of the nickel coatings.

The triple layer coating was twice the thickness of the single layer nickel coating (Table 2). The triple layer coating frequently produces better protection than the single layer coating due to the increased thickness and also because of the overlapping layers. The triple layer coating will failure if an aligned damage occur in these three layers.

\subsection{Electrochemical Tests}

The electrochemical results are shown in Figure 4 and Figure 5. It is possible to see that the demagnetized sample (OMF) presented a typical active state behavior with the values of OCP falling during the first $1000 \mathrm{~s}$ of exposure to the solution. After this period, the sample surface stabilized and reached the stable potential of $-0.78 \mathrm{~V} / \mathrm{SCE}$ at the end of the 10,600 s (Figure 4).

The anodic potentiodynamic polarization curve (APPC) showed an increase of the current density indicating a sample active-state behavior during the scanning within the tested potential range (Figure 5). 
Table 2. Average values and standard deviation of the coating thickness measurements.

\begin{tabular}{ccc}
\hline Coating & Average $(\mu \mathrm{m})$ & Standard deviation $(\mu \mathrm{m})$ \\
\hline Single layer & 7.64 & 0.65 \\
Triple layer (Ni-Cu-Ni) & 14.26 & 1.23 \\
Layer A (Ni) & 3.82 & 0.26 \\
Layer B (Cu) & 2.64 & 0.27 \\
Layer C (Ni) & 7.82 & 0.82 \\
\hline
\end{tabular}

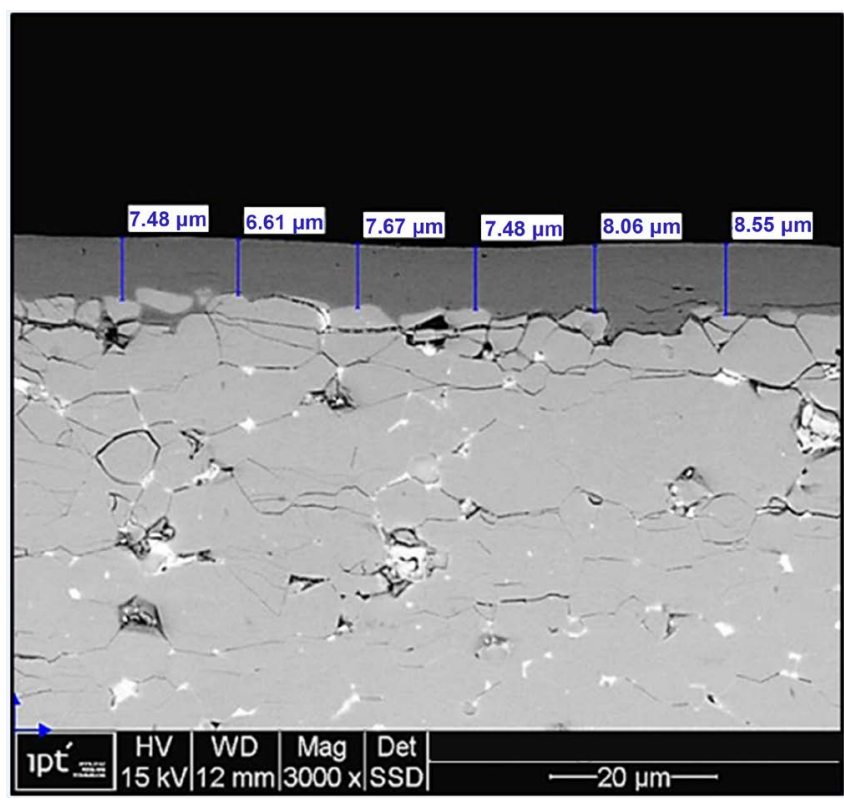

(a)

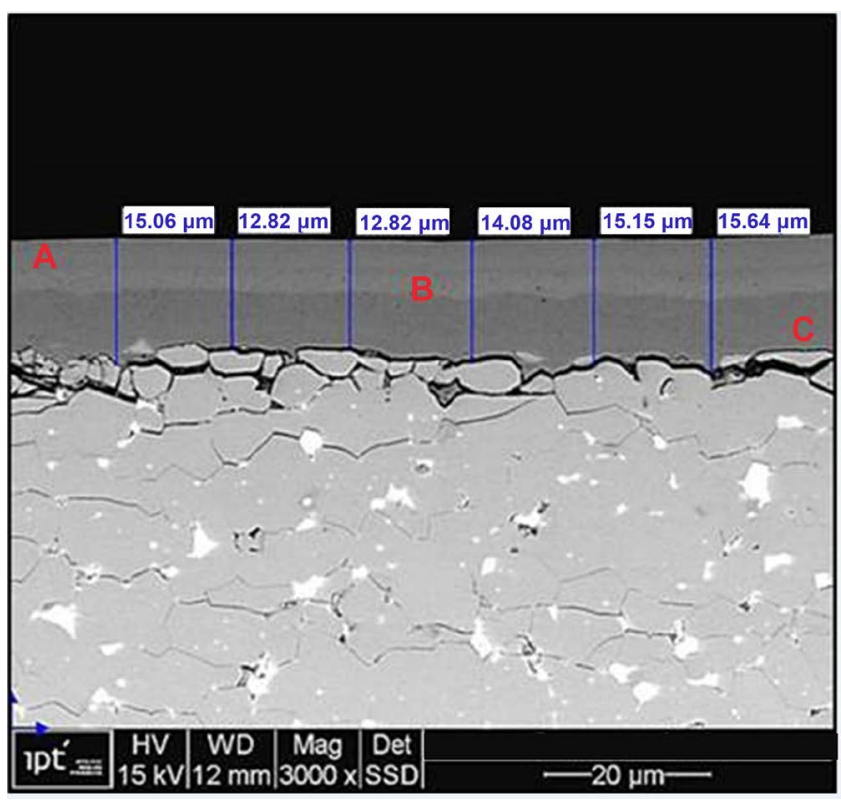

(b)

Figure 3. SEM images of Nd-Fe-B nickel coatings. (a) Single coating (HT demagnetized); (b) Triple coating (MFO demagnetized). 


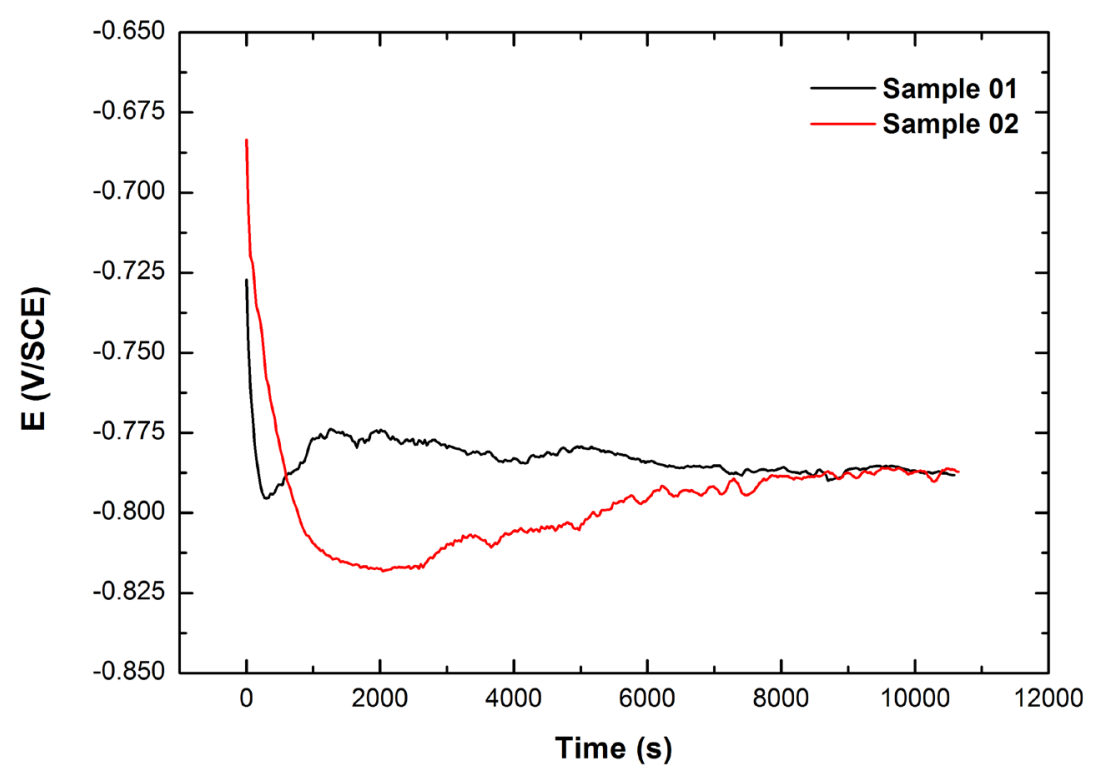

Figure 4. Open circuit potential $\times$ time curves. Black curve: Sample 01. Red curve: Sample 02. Both samples were demagnetized (OMF).

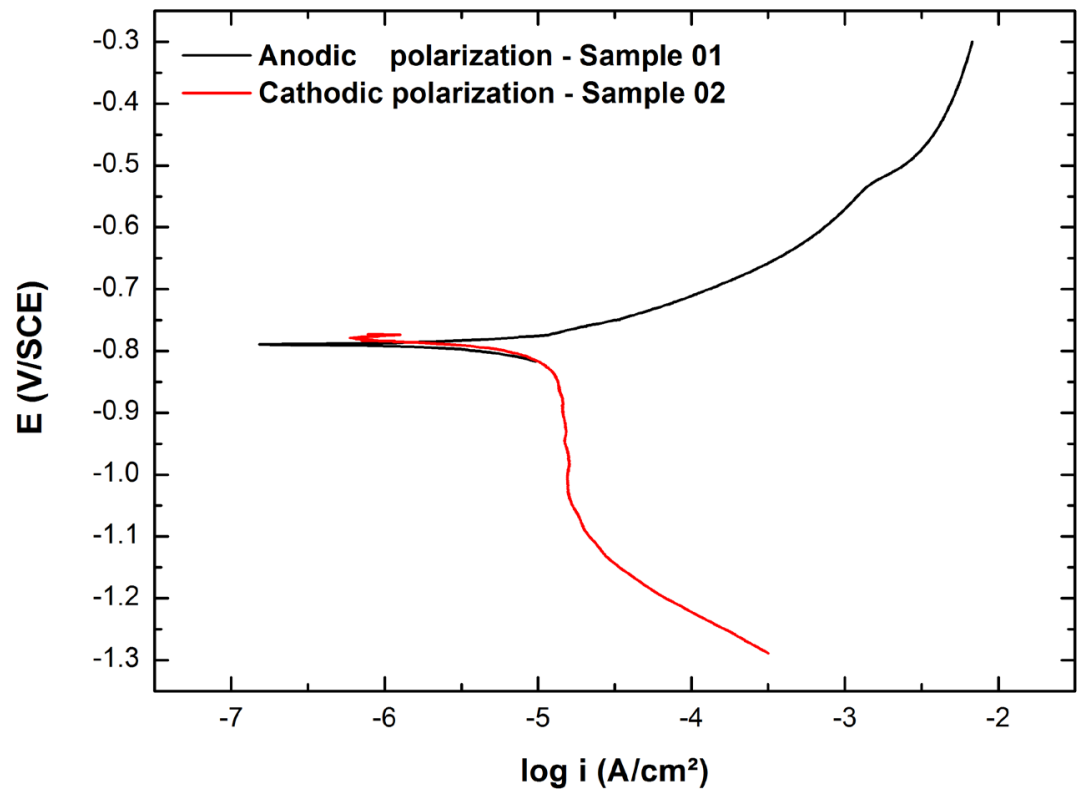

Figure 5. Potentiodynamic polarization curves. Black curve: APPC. Red curve: CPPC. Scan rate: $0.166 \mathrm{mV} / \mathrm{s}$. Both samples were demagnetized (OMF).

The cathodic potentiodynamic polarization curve (CPPC) presented constant values of current densities between $10-5 \mathrm{~A} / \mathrm{cm}^{2}$ and $10-4.5 \mathrm{~A} / \mathrm{cm}^{2}$ within the potential range from $-0.85 \mathrm{~V} / \mathrm{ECS}$ to $-1.10 \mathrm{~V} / \mathrm{ECS}$. This can be ascribed to the reduction of dissolved oxygen at the metal/electrolyte interface. From -1.10 V/ECS to $-1.30 \mathrm{~V} / \mathrm{ECS}$, the current densities increased due to $\mathrm{H}_{3} \mathrm{O}^{+}\left(\mathrm{H}^{+}\right)$ions reduction generating $\mathrm{H}_{2}$ gas (Figure 5).

The samples were analyzed by SEM-FEG after both anodic and cathodic polatizations. The images are presented in Figure 6. 


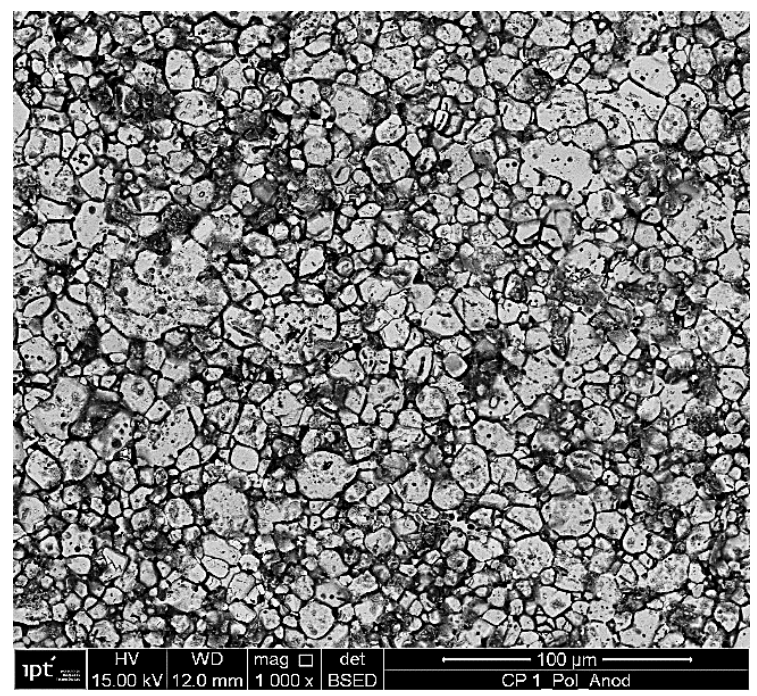

(a)

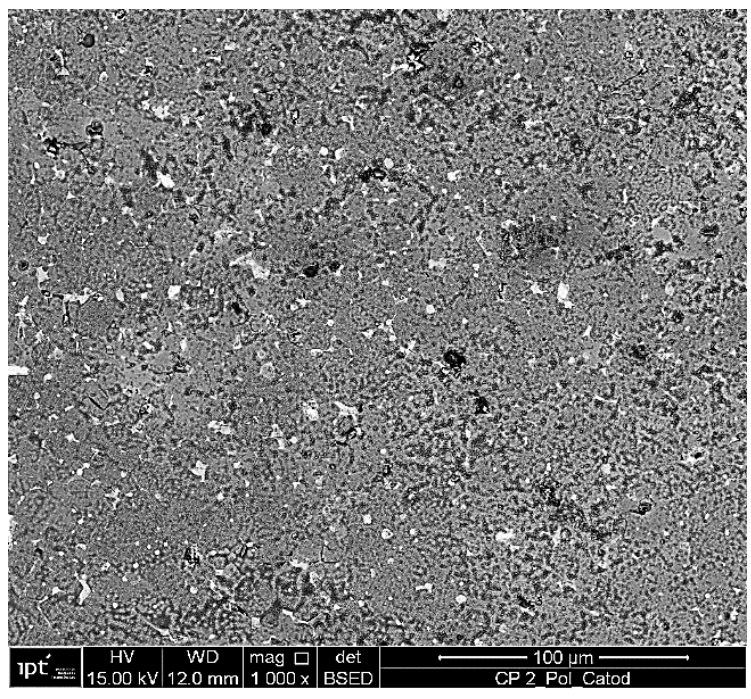

(b)

Figure 6. SEM-FEG sample images after potentiodynamic polarization curves. (a) After APPC; (b) After CPPC.

It is possible to see that the surface of the sample suffered strong intergranular corrosion after APPC. After the CPPC, the surface was roughened due to the period of exposure to the solution during the OCP monitoring which preceded the cathodic polarization.

\subsection{Salt Spray Tests}

The images of the samples before and after the salt spray tests are presented in Table 3 (magnetized samples) and Table 4 (OMF demagnetized samples).

The three magnetized samples suffered a slight superficial attack in the first 24 $\mathrm{h}$ of exposure. On the second day, there was one localized corrosion point on sample 2. After $72 \mathrm{~h}$, two samples presented localized corrosion (samples 2 and 3) and sample 1 presented only spots on its surface, Table 3. 
Table 3. Salt spray tests. Magnetized samples.

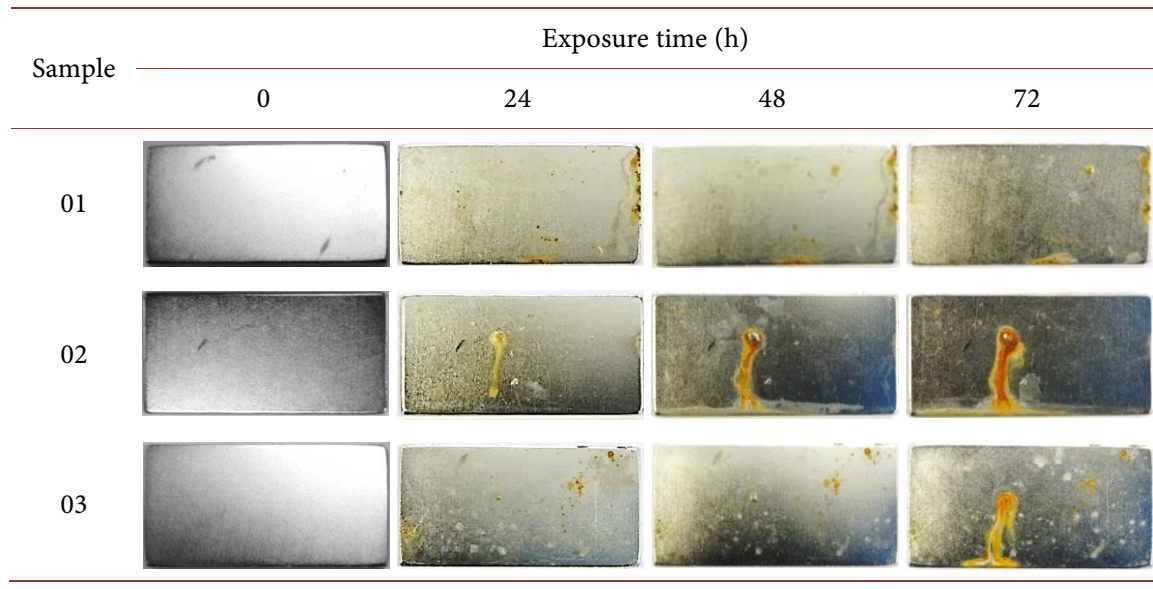

Table 4. Salt spray tests. Demagnetized (OMF) samples.

\begin{tabular}{|c|c|c|c|c|}
\hline \multirow{2}{*}{ Sample } & \multicolumn{4}{|c|}{ Exposure time (h) } \\
\hline & 0 & 24 & 48 & 72 \\
\hline \multicolumn{5}{|l|}{01} \\
\hline \multicolumn{5}{|l|}{02} \\
\hline 03 & & & & \\
\hline
\end{tabular}

The three demagnetized samples suffered localized corrosion in the first $24 \mathrm{~h}$ of exposure. Although they were already corroded, the samples were kept in the chamber to verify whether other corrosion points might appear, but no more points occurred.

One of the magnetized samples was demagnetized (OMF) and cut transversely for SEM-FEG analyses of the cross section after salt spray tests (Figure 7).

Salt spray test made a damage on the substrate through discontinuities of the nickel coating triple layer. This corrosion occurred between the grains of the magnetic alloy in the rich RE phase, Figure 7.

Although the SEM images show intergranular corrosion, the ferromagnetic phase (iron-rich phase) must have also been corroded because it was possible to see red corrosion products on the samples after the immersion tests, Table 3 and Table 4.

Multilayer coatings aim at offering a great substrate protection because they present low probability of a substrate exposure. For the substrate corrosion to occur, the coating discontinuities of each coating layer must be aligned to expose the substrate [9]. During the salt spray tests, not all the samples suffered localized 


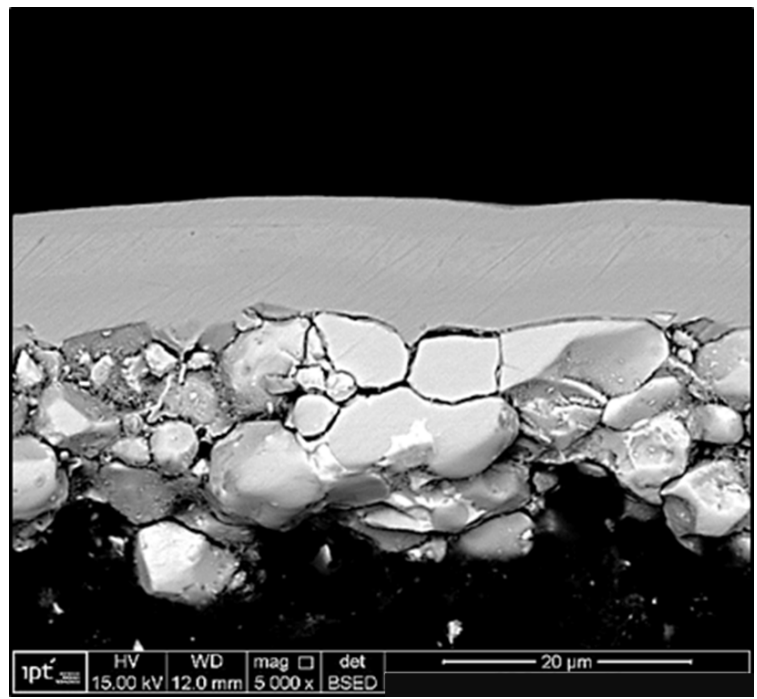

Figure 7. SEM-FEG image of cross section of the magnetized sample after salt spray test.

corrosion, others were superficially stained. This fact is justified by the mentioned intrinsic characteristic of the multilayer nickel coating.

\section{Conclusions}

The RE-Fe-B based magnets have multiphase complex microstructure and the rare-earth metals are intrinsically susceptible to corrosion. These magnets have a poor corrosion resistance and must be protected.

The commercial nickel coatings adhesion was investigated. The Nd-Fe-B without coating was studied by scanning electron microscopy and electrochemical tests (potential monitoring and potentiodynamic polarization). The interface magnet surface/coating was studied by scanning electron microscopy and the nickel-plated Nd-Fe-B commercial magnets were studied by salt spray tests.

The SEM microstructure analysis showed two most important phases: the ferromagnetic phase $(\phi)$ and the RE-rich phase. It was observed intergranular corrosion inside the substrate near the magnet surface/coating interface for both nickel coatings single and triple layers.

This corrosion probably occurred during the electrodeposition process and can affect the nickel coating adherence. Thus, efforts should be made to develop less aggressive electrodeposition processes to RE-Fe-B based magnets.

After the anodic polarization test, it was possible to see a strong intergranular corrosion. The RE-rich phase was preferentially attacked.

During the salt spray tests, not all the samples suffered localized corrosion and others were superficially stained. The Ni triple-layer coating presented a few corrosion points.

RE-Fe-B alloy magnets need to be protected with appropriate coatings to each environment to which they will be exposed. It is very important that the coating be maintained intact during the assembly or positioning of these magnets on the various devices in which they are currently employed. Coating damages which 
expose the substrate alloy will result in a shortening of the useful life of the devices.

\section{Acknowledgements}

The authors thank the IPT-Fipt for financial support for this work. The authors thank Rafael Augusto Camargo and Juliana Pereira Flor for their assistance during tests and characterization of magnets.

\section{Conflicts of Interest}

The authors declare no conflicts of interest regarding the publication of this paper.

\section{References}

[1] Rocio, M.A.R., da Silva, M.M., de Carvalho, P.S.L. and Cardoso, J.G. da R. (2012) Terras-raras: situação atual e perspectivas [Internet]. BNDES Setorial. https://web.bndes.gov.br/bib/jspui/handle/1408/1527?mode=full\&submit_simple= Mostrar+registro+em+formato+completo

[2] UNITED STATES GEOlOGICAL SURVEY (2016) Mineral Commodity Summaries Rare Earths. USGS, Reston.

http://minerals.usgs.gov/minerals/pubs/commodity/rare_earths/mcs-2016-raree.pdf

[3] Lima, I.B. and Leal Filho, W., Eds. (2016) Rare Earths Industry Technological, Economic, and Environmental Implications. Elsevier, Amsterdam.

[4] Brown, D.N. (2016) Fabrication, Processing Technologies, and New Advances for RE-Fe-B Magnets. IEEE Transactions on Magnetics, 52, 1-9. https://doi.org/10.1109/TMAG.2016.2535482

[5] Dent, P.C. (2012) Rare Earth Elements and Permanent Magnets (Invited). Journal of Applied Physics, 111, 07A721-07A721. https://doi.org/10.1063/1.3676616

[6] Schultz, L., El-Aziz, A.M., Barkleit, G. and Mummert, K. (1999) Corrosion Behaviour of Nd-Fe-B Permanent Magnetic Alloys. Materials Science and Engineering, A267, 307-313. https://doi.org/10.1016/S0921-5093(99)00107-0

[7] Rodewald, W. (2007) Rare-Earth Transition Metal Magnets. In: Handbook of Magnetism and Advanced Magnetic Materials, Wiley, 1-22. https://doi.org/10.1002/9780470022184.hmm406

[8] VACUUMSCHMELZE GMBH \& CO. KG (Germany) (2013) Coating. http://www.vacuumschmelze.com/index.php?id=1130

[9] Panossian, Z. (1993) Revestimentos metáLicos. In: Panossian, Z., Ed., Corrosão e proteção contra corrosão em equipamentos e estruturas metálicas, Instituto de Pesquisas Tecnológicas, São Paulo, 590-612. 